\title{
Potential and policy issues for sustainable development of wind power in China
}

\author{
Zhongfu TAN, H. W. NGAN (ه), Yang WU, \\ Huijuan ZHANG, Yihang SONG, Chao YU
}

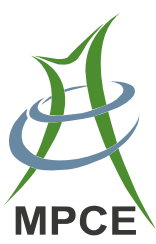

\begin{abstract}
This paper presents a macroscopic view on the prevailing policy and potential issues in respect of the sustainable wind power development in China. It starts by analyzing the characteristics of wind power resources and pin-pointing the relationship between the regulatory policies and various economic, taxation, legal and grid integration attributes relating to the wind power development. Then it follows by analyzing the status quo and capabilities of the wind power manufacturing industry in China including its operational efficiency and grid integration standards. The economic and environmental benefits are estimated by relating to the associated costing analysis in respect of the major contributing factors such as manufacturing, operational and financial factors. Results of the associated benefits analysis indicate that the use of the wind power generation helps to save a significant equivalent amount of standard coal
\end{abstract}

Received: 15 September 2013/Accepted: 26 October 2013/ Published online: 7 December 2013

(C) The Author(s) 2013. This article is published with open access at Springerlink.com

Z. TAN, H. ZHANG, Y. SONG, C. YU, School of Economics and Management, North China Electric Power University, Beijing, China

Z. TAN

e-mail: tanzhongfu@sina.com

H. ZHANG

e-mail: zhanghuijuan1213@163.com

Y. SONG

e-mail: allensoon@163.com

C. YU

e-mail: yu-chao@126.com

Z. TAN, School of Economics and Management, Shanghai

University of Electric Power, Shanghai, China

H. W. NGAN, Y. WU, Department of Electrical Engineering,

The Hong Kong Polytechnic University, Hong Kong, China

(凹) e-mail: eehwngan@polyu.edu.hk

Y. WU

e-mail: yang.wu@polyu.edu.hk consumption resulting to reduction of emission effectively. Finally, the potential of wind power development in China is shown to be affirmative and the sustainable energy policy is effectively implemented in China.

Keywords Wind power, Renewable energy policy, Sustainable development, Energy saving, Emission reduction

\section{Introduction}

Since the introduction of the Renewable Energy Law in 2005, the use of renewable energy for electricity generation in China has grown rapidly. The newly installed wind power capacity in China has roughly doubled every year since 2005 [1]. Innovative design for a different mix of energy generation is desirable [2]. It requires review on the current status of sustainable energy development, and justification on the different means of energy utilization [3]. Wind power has been deemed as a potential clean energy source world-wide [4], and China is no exception, but its use links to some social engagement with support of appropriate policy set to achieve specific targets [5]. In this paper, the current status of wind power development in China [6] has been explored from a macroscopic point of view covering the wind power resources, policy and legal issues, various capabilities and benefits and finally the prospective potential development concerns. The paper also includes comprehensive discussion on various aspects for justifying the regulatory measures and policy framework for supporting the sustainable energy development. The findings suggest that from both the economic and technical point of views wind power is a healthy, sustainable and efficient means to provide clean power for the energy market in China. A notable feature in the adopted 
approach lies on the analysis framework based on which the value of the relevant energy policies is presented. Analysis on the potential of China's wind power manufacturing industry is presented in the paper and indicates that development of the wind power industry will also open up new areas in manufacturing of both onshore and offshore wind power technologies which shall enable China to become a major player in the growing domestic and international markets. In this respect, findings indicate that the appropriate energy policy framework of wind power in China can help her to achieve its economic and environmental goals. The results of social-economic analysis also support that China regards wind power as a practical means to achieve a more sustainable and efficient energy portfolio. Finally, the contribution comes from the results of analysis for justifying development of wind power in China as a cleaner and more efficient option.

\section{Status quo of China's wind power development}

Since the 1970s, China has conducted four nationwide wind resource surveys. The first three were mainly resource investigations, while the fourth, undertaken since 2007, is a detailed investigation and assessment of national wind resources [7]. According to this detailed survey, the China Meteorological Administration (CMA) erected 400 wind towers with heights of 70,100 and $120 \mathrm{~m}$, and established a national wind measurement network [8]. Based on the analysis of the data from the exploitable areas, development potentials of wind power density grades 2, 3, 4 at heights of 50,70 , and $100 \mathrm{~m}$ are obtained as shown in Table 1. If wind resource regions with wind power density of grade 3 and above are considered exploitable, wind resource development potentials will be between 2 and 3.4 TW.

Wind power in China has entered the large-scale development phase. From 2006 to 2009, China's total wind power installed capacity doubled each year as shown in Fig. 1.

When compared to the five largest wind power countries, China's wind power capacity is comparable to that of the USA and much above countries such as India, Germany and Spain. Judging from the current exploitation of wind energy in China, about $2 \%$ [9] developed only, plus her rich offshore wind

Table 1 Exploitable potential of land-based wind resources (GW)

\begin{tabular}{llll}
\hline $\begin{array}{l}\text { Height } \\
\text { above } \\
\text { ground } \\
(\mathrm{m})\end{array}$ & $\begin{array}{l}\text { Grade } 4 \text { or } \\
\text { higher (wind } \\
\text { power density } \\
\left.\geq 400 \mathrm{~W} / \mathrm{m}^{2}\right)\end{array}$ & $\begin{array}{l}\text { Grade } 3 \text { or } \\
\text { higher (wind } \\
\text { power density } \\
\left.\geq 300 \mathrm{~W} / \mathrm{m}^{2}\right)\end{array}$ & $\begin{array}{l}\text { Grade } 2 \text { or } \\
\text { higher (wind } \\
\text { power density } \\
\left.\geq 200 \mathrm{~W} / \mathrm{m}^{2}\right)\end{array}$ \\
\hline 50 & 800 & 2,000 & 2,900 \\
70 & 1,000 & 2,600 & 3,600 \\
100 & 1,500 & 3,400 & 4,000 \\
\hline
\end{tabular}

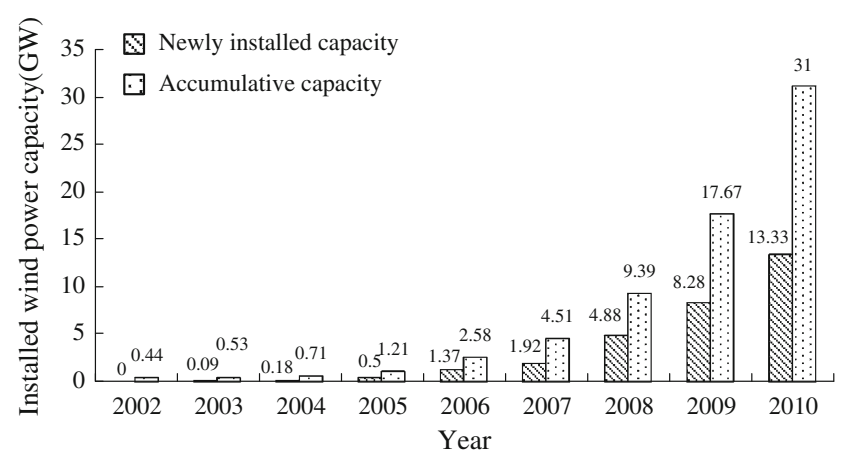

Fig. 1 Installed wind power capacity in China

energy, China has a great potential [10] to develop her wind power with the overall wind power distribution pattern. The wind resources mainly come from the north, northeast, northwest and eastern regions along the Pacific Ocean regions. It embraces regions along Hebei, Western Inner Mongolia, Jilin, Jiangsu coastal areas, Gansu Jiuquan and Xinjiang Hami forming the seven wind energy bases. Their annual average wind energy generation intensity is in the order above $150 \mathrm{~W} / \mathrm{m}^{2}$, and can be as high as $300 \mathrm{~W} / \mathrm{m}^{2}$ in other regions such as Western Inner Mongolia whilst the annual production hours are around five to six thousand. Hence, the wind power development in China is characterized as large-scale, centralized with long-distance transmission support. In the future, this large-scale development of wind farms will be continued in the northern China. At the same time, wind resource development in the east will take advantage of a good power grid infrastructure and a high potential wind power consumption capacity. Offshore wind power in China is in the early demonstration phase. In the near term, a gigawatt-scale offshore project will be started in order to gain experience in offshore technologies.

From the seasonal point of view, China's wind energy is mainly concentrated in spring and winter which is a good complement to the hydro power for the shortage in these two seasons. However, from the load distribution point of view, wind energy resources do not match well with the electricity load demand. Only those wind bases in Jiangsu and northeast are located within the loading zone; other wind resources are geographically far away from the load center making limited local consumption of the wind energy and hence the wind energy has to be transmitted to the loading centers via transmission network. However, the 12th Five-Year Plan will change the power generation structure in which new and renewable energy resources figure prominently. According to the plan, non-fossil fuel generation should account for $11.4 \%$ of total primary energy consumption by 2015, and renewable energy resources should be $20 \%$ by 2020 . In order to reach emission reduction targets, the proportion of new and 
renewable energy in China's overall energy mix will continually increase. Clean energy sources include hydro, biomass, wind, solar, and nuclear power. It further reckons that a modern energy industry in China will be based on energy conservation, domestic development, diversity and environment protection, to strengthen international cooperation and mutual benefit, adjust and optimize the energy structure, and build a safe, stable, economical and clean modern energy industry system. Although the Renewable Energy Law provides the legal framework to set out appropriate policy instruments, such as financial subsidy and taxation rebate, and technical guidelines to facilitate grid connection of wind power, the grid integration and consumption of wind power are still the critical issues to be resolved.

\section{Supports to wind power development in China}

Due to intermittency and instability issues, the installed capacity of wind power will be lower than that of hydro power and nuclear power by 2020 [11]. During the 12th Five-Year Plan development of wind power will carry on with the high speed growth inherited from the 11th and by its end the 12th Five-Year Plan can potentially see a total installed capacity of $130 \mathrm{GW}$. Wind power equipment manufacturing ability will also be improved significantly. Unlike the 11th Five-Year Plan which solely focused on installed capacity, the 12th Five-Year Plan focuses on both quality and quantity. Following the past few years of fast capacity, emphasis on quality is without doubt the necessary path for healthy development of the wind power industry. At the National Energy Work Conference held on 6th January, 2011, when Zhang Guobao, Director of the National Energy Administration at the time, spoke about the 12th Five-Year Plan, he repeatedly used terms like "grid integrated capacity" and "total actual power generation", clearly surpassing the 11th Five-Year Plan's limited aim on simple capacity installation.

\subsection{Manufacturing capability of wind power generators}

As China is encouraging development of new energy technology, it brings along rapid development of the manufacturing industry on the wind power generators. In 2005, the National Development and Reform Committee (NDRC) set a target of $70 \%$ of the market share of wind power generator equipment had to come from the domestic manufacturers and those wind farms not meeting the target were not allowed to be constructed. It provided competitive advantages for the domestic invested wind power generator manufacturing companies. As shown in Fig. 2, foreign invested companies took the lead on the market share of

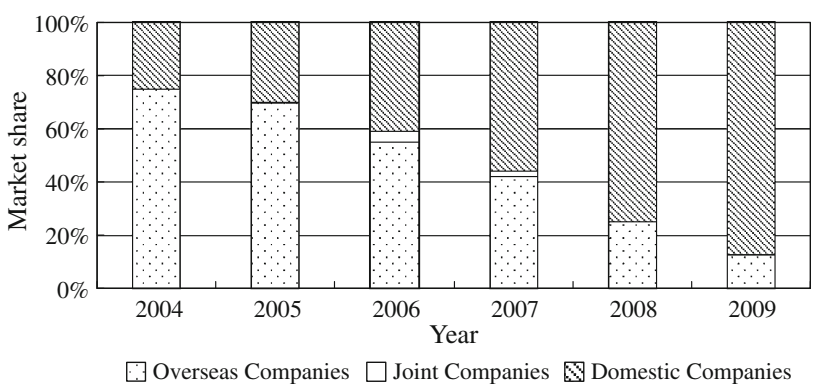

Fig. 2 Trend of market-share of newly installed wind power generators in China

more than $70 \%$ before 2005. Due to introduction of the protection policy and the obvious pricing advantages of the local production, the domestic market share in the new wind power generators increased drastically to $87 \%$ in the year 2009.

The huge demand of wind power generators in China provides a great opportunity for domestic manufacturing companies to expand their business. In terms of the manufacturing state-of-the-art of technology, MW level of wind power generators is the manufacturing norm and its market share in the newly installed generators have continuously increased more than $50 \%$ for the last three years. Manufacturing of multiple MW wind power generators is coming out in stages with domestic manufacturing capability of $3 \mathrm{MW}$ wind power generator followed by $5 \mathrm{MW}$ level unit on its way into production soon in China.

There were four Chinese wind turbine manufacturers in global top 10 largest wind turbine manufacturers [12], which indicates that wind turbine manufacturing industry in China has been strived into the world-class level. With the increase of wind turbine sales, the technology of wind power in China also gets improved. Stimulated by the development of offshore wind power, leading manufacturers of wind turbine and component begin to develop large-scale turbines, Chinese manufacturers, such as $\mathrm{Si}$ novel and Goldwind, also begin to develop large-scale wind turbines, and many enterprises succeed in developing wind turbines with and above 5 MW capacity. Wind turbines with three blades, horizontal axis, upwind, doublyfed, variable pitch, variable speed, and constant frequency take the initiative in Chinese wind turbine market, which is also the main technique in global wind turbine market. Besides, Chinese manufacturers also focus on the development of MW-class wind turbines with vertical axis, consistent with foreign leading manufacturers.

According to the Medium- and Long-term Plan for Renewable Energy Development and 12th Five-Year Renewable Energy Development Plan, wind power will further be developed and so will stimulate expansion of the wind turbine manufacturing sectors in turn. From 2010 to 


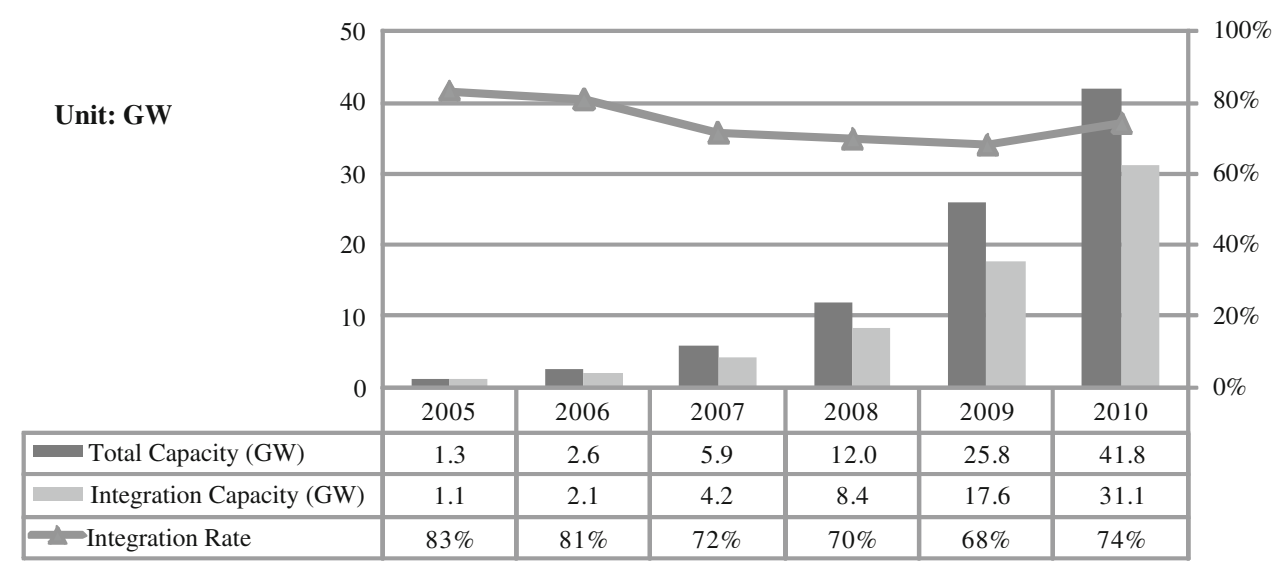

Fig. 3 Status of recent increase of wind generation installed capacity in China

2015, China's annual installed capacity is expected to reach about $15 \mathrm{GW}$, including about $14 \mathrm{GW}$ of land-based wind power and about $1 \mathrm{GW}$ of offshore wind power. Between 2015 and 2020, large-scale offshore wind power will begin to be developed rapidly, and the demand of wind turbine will reach $18 \mathrm{GW}$ of installed capacity per year, which includes $13 \mathrm{GW}$ of land-based wind turbines and $5 \mathrm{GW}$ of offshore wind turbines, while about $500 \mathrm{MW}$ of older wind turbines will need to be retired or transformed. From 2020 to 2030, $24 \mathrm{GW}$ of wind turbines will be needed annually, $19 \mathrm{GW}$ land-based and $5 \mathrm{GW}$ offshore, with $39 \mathrm{GW}$ of older wind turbines needing to be retired or transformed. Between 2030 and 2050, average annual wind turbine demand will be about $50 \mathrm{GW}$, including $44 \mathrm{GW}$ land-based and $6 \mathrm{GW}$ offshore, with about $400 \mathrm{GW}$ of older wind turbines being retired or reconstructed [11].

To meet the needs of the wind power supply chain and ensure wind turbine quality and reliability, advanced largecapacity turbine system R\&D capabilities should be improved further. The support policy and financial fund should pay more attention to basic technology research.

\subsection{Operational efficiency and grid integration}

Great prospects of the wind power industry in China stimulate the developers to consolidate their asset and get ready to raise their capital through the stock market for increasing their investment with some having already earmarked tens of MW wind power projects. However, the problem arising from the rapid development of the installed wind power generation capacity is escalated due to the lack of contingent capability to connect the generators to the grid. Hence, the more wind power generators built, the more serious of the problem caused by having more wind power generators left idle. The grid connection of the ever expanding wind generators appears to be a bottle-neck problem which can hardly be resolved in the short-term.
As shown in Fig. 3, the wind power installed capacity was expanding in the order of multiples since 2006 but the grid in-feed ratio was decreasing year by year. In 2007, it was the record year of highest annual growth rate up to $129 \%$ but in the same year there was the record of sharp decrease of energy in-feed to the grid. These facts clearly indicated that the wind power consumption capacity of the power company could not match with the rapid expansion of the wind power installed capacity. Further along the line in 2010, the rate of installed capacity of wind power generators slowed down and thus the wind power installation and grid in-feed ratio appeared to increase but the capacity of wind power not able to in-feed to the grid was still enlarging. In effect, the relationship between the growth rate of wind power installed capacity and the change of wind power in-feed ratio to the grid can be summarized as shown in Fig. 4.

On one hand, there are a number of factors to be considered for explaining the low ratio of power in-feed to the grid such as lack of an overall wind power consumption plan, insufficient support of transmission networks for the wind power generation, lag behind on the construction of the transmission infrastructure, tedious procedure to fulfill

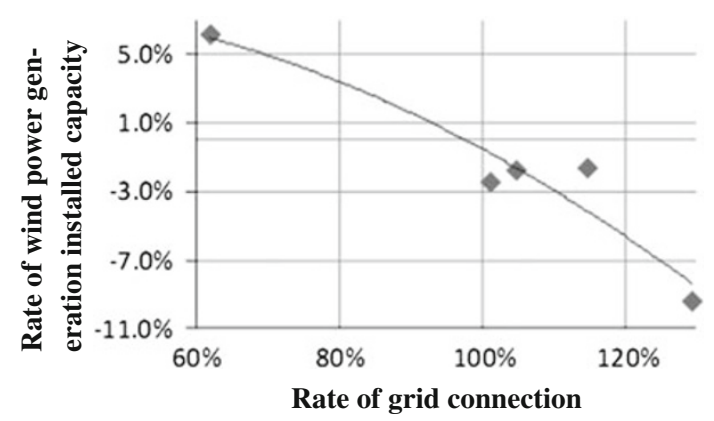

Fig. 4 Relationship between rate of wind generation installed capacity and rate of grid connection 
Table 2 Provincial wind generation installed capacity and capacity-not-yet-purchased

\begin{tabular}{|c|c|c|c|c|c|}
\hline \multirow[t]{2}{*}{ Province } & \multirow[t]{2}{*}{ Rank } & \multicolumn{2}{|l|}{ Wind capacity } & \multicolumn{2}{|c|}{ Non-purchased energy } \\
\hline & & Capacity (GW) & Proportion (\%) & Energy $(\mathrm{kWh})$ & Proportion (\%) \\
\hline Inner Mongolia & 1 & 9.2 & 35.6 & 19.86 & 72.0 \\
\hline Hebei & 2 & 2.8 & 10.8 & 2.64 & 9.6 \\
\hline Liaoning & 3 & 2.4 & 9.4 & 0.23 & 0.8 \\
\hline Jilin & 4 & 2.1 & 8.0 & 1.94 & 7.0 \\
\hline Heilongjiang & 5 & 1.7 & 6.4 & 1.13 & 4.1 \\
\hline Shandong & 6 & 1.2 & 4.7 & 0 & 0 \\
\hline Gansu & 7 & 1.2 & 4.6 & 1.81 & 6.5 \\
\hline Others & - & 5.3 & 20.5 & 0 & 0 \\
\hline
\end{tabular}

the grid connection requirements and uncertain benefits to the grid after connection, etc. In general, power companies are not eager to invest in expanding the wind consumption capacity. On the other hand, the distribution of the wind power is too centralized to the extent that the wind power consumption is beyond the grid's capability to handle. As shown in Table 2, those not yet purchased wind power in the year 2009 were all found in the provinces where wind power installed capacity was in the top of the list with more than $70 \%$ coming from the Inner Mongolia where the wind power installed capacity is $35.6 \%$ of that of the whole of China. Most of the provinces having wind power development on the frontier relatively suffer more seriously on the wind energy wastage aspects due to lacking wind power consumption capacity for matching the increase of installed wind power capacity. Whilst for those provinces whose wind power capacity is lower, they have a relatively smaller share of the generation source of the province. The power company has a better control and dispatch of their wind energy output and in effect achieves higher wind energy efficiency.

China's geographical imbalance of electric load and energy resources results in the key characteristics of transmission from west to east and mutual support between north and south grids. After sustained reforms of power infrastructure and the power market, China has established an interconnected grid network of regional grid infrastructures, with provincial grids as the major operators in practice. As China's greatest wind resources are in the north, far from load centres and the power grid framework, it will develop several large wind power bases, with capacities in the tens of gigawatts scale of wind base groups by 2050 developed in west Inner Mongolia and other regions [12]. Integration and accommodation of wind power in the power network have to face with many constraints, however, such as wind power output, system load, power source structure, regulation capability, power transmission scale and operation methods. These factors, which will continue to change, pose major challenges to the integration and accommodation of wind power. Seeing that China's power system is mainly based on coal generation, there is little scope for system balance dispatching. Integration and accommodation of a large volume of wind power from northern wind bases will be a challenge due to insufficient peak adjustment capacity and limited transmission capabilities to handle the overabundance of wind power.

Existing support policies for large-scale wind power integration are inadequate. They focus mainly on wind farm tariffs, grid access subsidies and cost sharing, rather than on obligations and conflicts of interest. Accommodating wind power in the national power system requires not only technical solutions but also reforms in management, policies and regulations. The National Energy Administration initiated a wind power grid integration and accommodation study showing that China could achieve a wind energy economic potential of $160 \mathrm{GW}$ to $200 \mathrm{GW}$ by 2020 , by optimising systematic power development plans, encouraging appropriate deployment of pump storage capacity and gas power peak adjustment, as well as rational development of interprovince power transmission. To achieve this potential, administrative co-ordination needs to be strengthened to increase the provincial capacity of wind power accommodation and promote long-distance inter-provincial and interregional transmission of wind power.

Further policy supports, such as establishing pricing policies to encourage grid-friendly wind power projects, could include performance-based incentives or ancillary service cost-sharing. National directives should be strengthened on inter-provincial/inter-regional power exchange. Intra-province wind power transmission cost could be shared through local power tariffs. Inter-provincial and inter-regional UHV transmission costs should be covered by purchase prices and sale prices in the target province or region. In addition, mutually agreed quota systems and liberalised market mechanisms should be explored and implemented to promote inter-regional power exchange. 
In short, wind power and power system development plans need to be co-ordinated, along with technology roadmaps, system standards and arrangements for power grid scheduling, dispatch and operation strategy. The implementation of flexible, well-developed electricity market mechanisms and incentives is required in order to optimise system operation and eliminate institutional barriers in the near and midterm. In the long term, the power system should be comprehensively transformed by technical and institutional innovation.

\section{Benefits for developing wind power in China}

Determination of the economic benefits of the wind power industry mainly depends on a few factors such as original investment, operational cost, equivalent effective hours per annum and on-grid feed-in tariff [13]. The original investment includes those on the wind power generation units, civil engineering, electrical engineering, installation expenses, financing cost and other miscellaneous cost on land acquiring and surveying fees etc. out of which the wind power generation units have the highest share. Since the cost, scale and time schedules of wind power development can differ remarkably from region to region, the economically exploitable wind power potential is estimated by using the two price metrics, namely, feed-in tariff (FIT) and full cost (FC). By referring to the geographical information of the regions, the FIT is based on the economic evaluation of wind projects, including annual electricity production of a unit area, assumed internal rate of return (IRR) and installation cost. This tariff does not take into account costs of grid connection and transmission as it will be included in the other price metric, FC, which is determined as FIT plus local grid access cost and interprovincial transmission costs.

With continuous improvements in wind power scale and technology, the wind turbine unit cost may fall to match the unit cost of coal-fired thermal power. Within the next
10 years or so, wind power is expected to be able to compete with conventional energy technologies. According to the Technology Roadmap: Wind Energy [14], wind turbine prices still have room for cost reductions of $10 \%-20 \%$ in constant prices as shown below. By taking the current average onshore wind farm operational cost as about $25 \%$ of total wind power cost, the wind power O\&M costs on land can reasonably be assumed to be around $¥ 0.10 / \mathrm{kWh}$ [13]. At the same time, as decreasing wind turbine prices, wind farm investment costs and O\&M costs are lowering the cost of wind power generation in China, higher thermal power prices will be difficult to avoid, because of higher coal mining costs and prices. It is expected that after 2020, even without fossil energy resource taxes or environmental taxes, carbon taxes, etc., wind power costs and prices will tend to match those of thermal power, while after 2020, wind power tariffs will be lower than coal power tariffs without considering wind power consumption and long-distance transmission factors as summarized in Table 3.

Some of the benefits among many others for developing the wind power in China such as those concerning the economic and environmental issues are discussed in the following context.

\subsection{Economic benefits of wind power investment}

Due to the production surplus on wind power generation, there is a global trend of price reduction on the newly installed wind power units which appears to have stayed at the bottom level in recent years. In China, the price levels of the wind power generation units have also been falling continuously. As a result, it makes the percentage share of the total investment costs lower for the wind power units. However, following the reversing trend on having more demand of wind power generation units, rebound on the asking price is not excluded. Analysis on the economic benefits requires understanding of the investment price model of the wind power generation unit of which its break-even price in the year $i$ is derived as shown in (1).

Table 3 Technically exploitable potential of land-based wind resources (GW)

\begin{tabular}{|c|c|c|c|c|c|}
\hline & & 2010 & 2020 & 2030 & 2050 \\
\hline \multirow[t]{3}{*}{ Unit investment (¥/kW) } & Land-based & $8,000-9,000$ & 7,500 & 7,200 & 7,000 \\
\hline & Near offshore & $14,000-19,000$ & 14,000 & 12,000 & 10,000 \\
\hline & Far offshore & - & 50,000 & 40,000 & 20,000 \\
\hline \multirow[t]{3}{*}{ O\&M cost $(¥ / \mathrm{kWh})$} & Land-based & 0.10 & 0.10 & 0.10 & 0.10 \\
\hline & Near offshore & 0.15 & 0.15 & 0.10 & 0.10 \\
\hline & Far offshore & - & 0.30 & 0.20 & 0.10 \\
\hline \multirow[t]{3}{*}{ Projected average feed-in tariff ( $¥ / \mathrm{kWh})$} & Land-based & 0.57 & 0.51 & 0.48 & 0.45 \\
\hline & Near offshore & $0.77-0.98$ & 0.77 & 0.60 & 0.54 \\
\hline & Far offshore & - & $>2$ & 2 & 1 \\
\hline
\end{tabular}


Table 4 Major parameters of the wind power configuration

\begin{tabular}{lll}
\hline Parameter & Value & Potential trend \\
\hline$C$ & $¥ 4,000 / \mathrm{kW}$ & $\pm 10 \%, \pm 20 \%$ \\
$\alpha$ & $70 \%$ & $-10 \%$ \\
$\omega$ & $10 \%$ & \\
$\mu$ & $8.5 \%$ & \\
$r$ & $8 \%$ & \\
$n$ & 20 years & $\pm 100, \pm 300, \pm 500$ \\
$T$ & $2,200 \mathrm{~h}$ & \\
$I$ & $2 \%$ & \\
\hline
\end{tabular}

$P_{i}=\frac{\left[\frac{r(1+r)^{n}}{(1+r)^{n}-1} \times \frac{C G}{\alpha}+M_{i}\right](1+\mu)}{G T_{i}(1-I)}$

where $M_{i}$ is the operational cost in the year $i$; $C$ is the per $\mathrm{kW}$ manufacturing cost of the wind power unit; $G$ is the total installed capacity of the wind power units; $I$ is the power consumption of the station service in percentage; $\alpha$ is the wind power manufacturing cost in percentage of the original investment; $n$ is the period of depreciation in years; $r$ is the discount rate; $T_{i}$ is the equivalent effective hours in the year $i ; \mu$ is the value-added tax rate.

Assuming that the total present value of the operating cost is calculated as a faction $(\omega)$ of the original investment and all other factors remain steady and constant, the breakeven investment price is re-written as in (2).

$P=\frac{\frac{r(1+r)^{n}}{(1+r)^{n}-1} \times \frac{C}{\alpha}(1+\omega)(1+\mu)}{T(1-I)}$

It indicates that when the feed-in price exceeds $P$, wind power generator developers are profit making. On the contrary, they will lose out when the feed-in price is lower than $P$.

By taking the major parameters with typical values as listed in Table 4, estimation on the wind power manufacturing cost, its ratio in terms of the original investment, and effective equivalent hours are made and based on which the break-even price $(P)$ is determined. From the results obtained as shown in Table 5, the benchmark feed-in tariff is set in accordance with the four types of wind energy resource areas, i.e., $¥ 0.51, ¥ 0.54, ¥ 0.58$ and $¥ 0.61$ per $\mathrm{kWh}$ which ensure normal operation of the respective wind farms. Furthermore, individual local government introduces various compensation schemes encourage wind power development making the feed-in price more than $¥ 0.7 / \mathrm{kWh}$ and for those projects supported with CDM [15], the benefit can be more than $¥ 0.8 / \mathrm{kWh}$. Hence, the prevailing pricing mechanism in China provides the economic benefits which serve to drive the wind power industry for continuous and sustainable expansion on scale and quality of the wind power development in China.

Taking the case of wind power generation unit with manufacturing cost of $¥ 4,000 / \mathrm{kW}$ and about $60 \%$ of the original investment, the profit making level in the four types of wind energy resource areas is calculated as shown in Fig. 5. Although the feed-in prices are set after taking care of the different type of wind energy resources, those in the resources rich areas still come with advantageous positions of having more effective equivalent hours and obvious better level of profit making capability. From the angle of view of encouraging a balance and fair wind power development on different parts of the whole country, there is a need for relevant regulatory authority to make adjustment on the feed-in tariff based on their type and areas of the wind energy resources by increasing the rate of the incremental tariff so as to reduce the level of difference in profit. Based on the estimated results and set the feed-in price of the different wind resource areas as $¥ 0.48$, $¥ 0.53$, $¥ 0.60$, ¥0.66 per $\mathrm{kWh}$, their level of difference in profit made would be reduced significantly as shown in Fig. 6.

\subsection{Environmental benefit}

Due to tight supply of energy and its obvious environmental problems, the benefits on the energy saving and emission reduction effects of using wind power attract much attention. In effect, every kWh of wind power energy

Table 5 Manufacturing cost of generation unit, its ratio of manufacturing cost to the original investment and contrast of profit and loss subject to varying hours of grid connection (unit: $¥ / \mathrm{kW}$, hour, $¥ / \mathrm{kWh}$ )

\begin{tabular}{|c|c|c|c|c|c|c|c|c|c|c|c|c|c|c|c|}
\hline \multirow{2}{*}{$\frac{\alpha}{T}$} & & \multicolumn{7}{|l|}{$60 \%$} & \multicolumn{7}{|l|}{$70 \%$} \\
\hline & & +500 & +300 & +100 & 2,200 & -100 & -300 & -500 & +500 & +300 & +100 & 2,200 & -100 & -300 & -500 \\
\hline \multirow[t]{5}{*}{$C$} & $+2 \%$ & 0.368 & 0.397 & 0.431 & 0.451 & 0.473 & 0.522 & 0.584 & 0.315 & 0.340 & 0.370 & 0.387 & 0.405 & 0.448 & 0.500 \\
\hline & $+1 \%$ & 0.337 & 0.364 & 0.395 & 0.413 & 0.433 & 0.479 & 0.535 & 0.289 & 0.312 & 0.339 & 0.354 & 0.371 & 0.410 & 0.459 \\
\hline & 4,000 & 0.306 & 0.331 & 0.360 & 0.376 & 0.394 & 0.435 & 0.486 & 0.263 & 0.284 & 0.308 & 0.161 & 0.338 & 0.373 & 0.417 \\
\hline & $-10 \%$ & 0.276 & 0.298 & 0.324 & 0.338 & 0.354 & 0.392 & 0.438 & 0.236 & 0.255 & 0.277 & 0.290 & 0.304 & 0.336 & 0.375 \\
\hline & $-20 \%$ & 0.245 & 0.265 & 0.288 & 0.301 & 0.315 & 0.348 & 0.389 & 0.210 & 0.227 & 0.247 & 0.258 & 0.270 & 0.298 & 0.334 \\
\hline
\end{tabular}




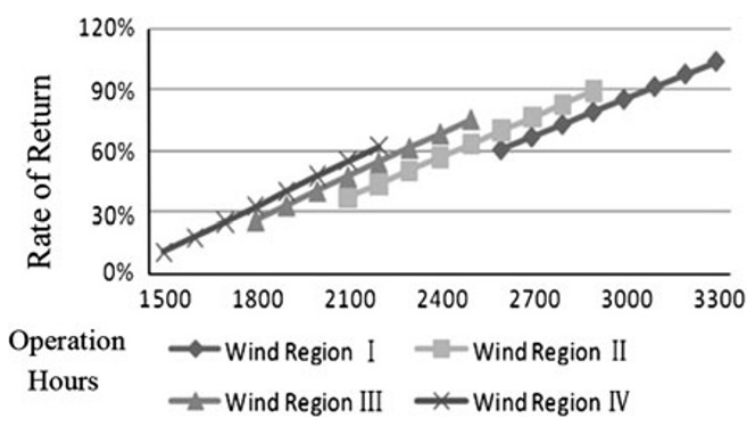

Fig. 5 ROR of different wind regions

supplied to the grid is equivalent to a saving of $340 \mathrm{~g}$ standard coal consumption and, at the same time, a reduction of $0.983 \mathrm{~kg}$ of $\mathrm{CO}_{2}, 0.698 \mathrm{~g}$ of $\mathrm{SO}_{2}, 0.65 \mathrm{~g}$ of $\mathrm{N}_{\mathrm{x}} \mathrm{O}_{\mathrm{y}}$ and $0.355 \mathrm{~g}$ of solid particulate emission [16]. Among the clean energy sources, wind power is the most competitive one and is having the greatest potential of development. As the installed capacity of wind power generators keeps on expanding, the above mentioned benefits and contribution would become more and more obvious and outstanding. The relative environmental benefits of wind power and coal-fire power can be realized by considering the following five major factors as contained in (3) representing the emission reduction capability of the wind power generation. Here, TSP stands for total suspended particulates.

$E_{\mathrm{CO}_{2} / \mathrm{SO}_{2} / \mathrm{NO}_{\mathrm{x}} / \mathrm{TSP}}=\lambda G_{T} T_{a v g}\left(1-I_{\text {avg }}\right) \eta_{\mathrm{CO}_{2} / \mathrm{SO}_{2} / \mathrm{NO}_{\mathrm{x}} / \mathrm{TSP}}$,

where $G_{T}$ is the total wind power installed capacity; $\lambda$ is the percentage of power connected to the grid; $T_{a v g}$ is the average equivalent effective hours in use p.a.; $I_{\text {avg }}$ is the average power consumption of the station services; and $\eta_{\mathrm{CO}_{2} / \mathrm{SO}_{2} / \mathrm{NO}_{\mathrm{x}} / \mathrm{TSP}}$ is the respective rate of emission of $\mathrm{CO}_{2}, \mathrm{SO}_{2}, \mathrm{NO}_{\mathrm{x}}, \mathrm{TSP}$.

By referring to the emission reduction calculation based on the 50.1 billion of $\mathrm{kWh}$ wind power generation though out China in the year 2010, energy saving by the wind power generation is equivalent to around 17 million tons of standard coal consumption and emission reduction of 49 million tons of $\mathrm{CO}_{2}, 35$ thousand tons of $\mathrm{SO}_{2}, 33$ thousand tons of $\mathrm{NO}_{\mathrm{x}}$ and about 18 thousand ton of TSP. According to the above analysis, it justifies that the wind power installation capacity in China has grown rapidly in the past decade though its rate may slow down a bit in the coming years. As forecast by the China Association of Comprehensive Resources Utilization [2], the wind power installed capacity by 2015 will be around $110 \mathrm{GW}$ to $130 \mathrm{GW}$, average rate of expansion is around $21 \%-25 \%$ p.a.; and by 2020 , the wind power installed capacity will be around $200 \mathrm{GW}$ to $230 \mathrm{GW}$, average rate of expansion is around

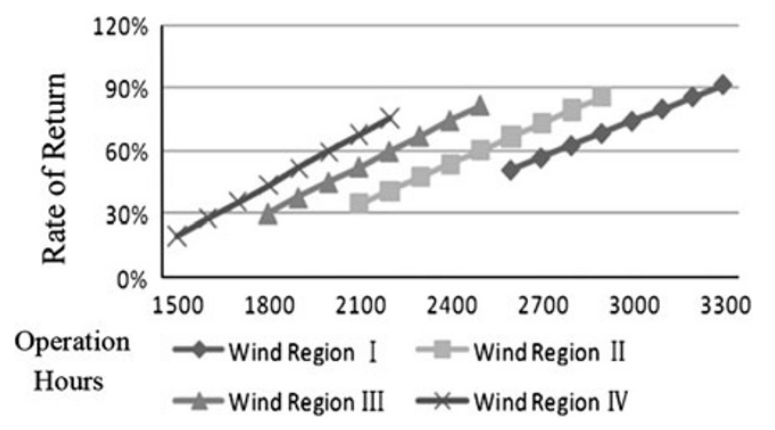

Fig. 6 ROR after price adjustment

$17 \%-19 \%$ p.a. Following maturity on the technical knowhow, the ratio of wind power connection to the grid is increasing up to $80 \%-90 \%$ which is close to the level of the leading wind power countries in Europe and USA. The annual equivalent effective hours of utilization is mainly affected by the wind quality of the specific wind farm. If the newly installed wind power projects do not cause too much change on the distribution among the wind energy resource areas, the average equivalent effective hours of utilization in the whole country remains more or less equal to the current level. By the same token, the power consumption of the station services, which is regarded as a basic index for maintaining normal operation of the wind farm, can be viewed as a parameter of the stability aspect. Regarding the rate of emission, it is mainly linked to the standard coal consumption of the coal-fire power plant and its environmental protection techniques. Following extension on scale of the coal-fire generation, complete combustion of coal is more likely making the consumption of coal for generation decrease gradually. Improvement of the environmental protection facilities further helps to reduce the rate of emission. A summary of the above analysis is shown in Table 6 which provides an estimated effect and benefits of energy saving and emission reduction by using wind power in China.

Based on figures since 2009, standard coal consumption for $6,000 \mathrm{~kW}$ and above power plant in China is about 915 million tons which has been increasing at a rate of $6.3 \%$ in recent years. By 2015, wind power may help to save more than $5 \%$ of the coal consumption in China and the benefits of such energy saving and emission reduction will further be extended. As projected from the analysis results, the benefits of energy saving and emission reduction of wind power continue to be promising. In fact, as an agreement in the Copenhagen 2009 Protocol, China promised to join in the international community effort to reduce $15 \%$ of her energy needs by 2020 which is regarded as an important commitment and promise to developing wind power in China. By considering the lifecycle energy consumption 
Table 6 Estimated effect and benefits of energy saving and emission reduction by using wind power in China

\begin{tabular}{llll}
\hline Year & & 2015 & 2020 \\
\hline Parameters & Installed capacity $(\mathrm{GW})$ & $110-130$ & $200-230$ \\
& Ratio of grid connection & $80 \%-85 \%$ & $85 \%-90 \%$ \\
& Operation hours (h) & $2,050-2,150$ \\
& Rate of station services power consumption & $2 \%$ & 330 \\
& Coal consumption for generation $(\mathrm{G} / \mathrm{kWh})$ & $62.5-82.3$ & 320 \\
Prediction of energy saving & Quantity of coal substitute (Mtce) & $1.7-2.2$ & $117.0-149.4$ \\
and emission reduction & $\mathrm{CO}_{2}$ reduction $\left(10^{8}\right.$ ton) & $12.0-15.8$ & $3.2-4.0$ \\
& $\mathrm{SO}_{2}$ reduction $\left(10^{4}\right.$ ton $)$ & $11.2-14.7$ & $22.4-28.7$ \\
& $\mathrm{NO}_{\mathrm{x}}$ reduction $\left(10^{4}\right.$ ton $)$ & $6.1-8.0$ & $20.9-26.7$ \\
\hline
\end{tabular}

and emission of wind power, the emissions and avoided external costs compared with conventional energy are shown in Table 7 . Wind power can replace 130 million tce (tones of coal equivalent) by 2020, 260 million tce by 2030, and 660 million tce by 2050 (taking into account improved thermal power technologies and lower coal consumption per kilowatt-hour of power). Annual $\mathrm{CO}_{2}$ emission reductions are expected to amount to 300 million tones (Mt) by 2020, $600 \mathrm{Mt}$ by 2030 and 1,500 Mt by 2050 [17]. In addition, annual $\mathrm{SO}_{2}$ emission reductions are expected to be 1.1 Mt by 2020,2.2 Mt by 2030 and $5.6 \mathrm{Mt}$ by 2050 . The $\mathrm{CO}_{2}$ reduction potential of wind power in different areas in future 40 years are shown in Fig. 7.

\subsection{Benefit on mitigation of climate change}

By replacing coal power, clean, non-polluting wind power can have significant environmental benefits by emission reduction of the pollutants generated by combustion of fossil fuels. The pollutants are related not only to global warming but also to other environmental impacts such as air pollution, acid precipitation, ozone depletion, forest destruction and emission of radioactive substances [18], which will further cause or exacerbate public health problems, including respiratory problems, skin disease, cancer, and so on. By emission reduction of the pollutants, many major environmental problems and related social health issues will be alleviated.

First, Acid rain caused by the air pollutants, $\mathrm{SO}_{2}$ and $\mathrm{NO}_{\mathrm{x}}$ will be mitigated. As the global largest coal consumer, the acid rain of China is mainly caused by combustion of coal with high sulphur content, and is sulfuric acid type. The damages of acid rain are showed in several aspects, such as impacting the rules of season changes and diurnal changes, causing smog, public health issues via reduction of sun radiation, damaging the ecosystems, destroying the forest, and damaging buildings, etc. Besides, attention is also given to other substances, such as VOCs, chlorides, ozone and trace metals that may participate in a complex set of chemical transformations in the atmosphere, resulting in acid precipitation and impacting human health. The emission of above pollutants will be reduced by substituting wind power for coal power, and then the pollution, acid rain, will also be mitigated.

Second, Ozone layer depletion will slow down. Ozone depletion is caused by the emissions of CFCs, halons (chlorinated and brominated organic compounds) and $\mathrm{NO}_{\mathrm{x}}$, and can lead to increased levels of damaging UV radiation

Table 7 Emissions and benefits of wind versus coal and natural gas for electricity

\begin{tabular}{|c|c|c|c|c|c|c|c|c|c|}
\hline & \multicolumn{6}{|c|}{ Emissions } & \multicolumn{3}{|c|}{ Benefits } \\
\hline & $\begin{array}{l}\text { Onshore } \\
\text { wind }\end{array}$ & $\begin{array}{l}\text { Offshore } \\
\text { wind }\end{array}$ & $\begin{array}{l}\text { Average } \\
\text { wind }\end{array}$ & $\begin{array}{l}\text { Hard } \\
\text { coal }\end{array}$ & Lignite & NGCC & $\begin{array}{l}\text { Vs. } \\
\text { coal }\end{array}$ & $\begin{array}{l}\text { Vs. } \\
\text { Lignite }\end{array}$ & $\begin{array}{l}\text { Vs. } \\
\text { NGCC }\end{array}$ \\
\hline Carbon dioxide (g) & 8 & 8 & 8 & 836 & 1,060 & 400 & 828 & 1,051 & 391 \\
\hline Methane (mg) & 8 & 8 & 8 & 2,554 & 244 & 993 & 2,546 & 236 & 984 \\
\hline Nitrogen oxides (mg) & 31 & 31 & 31 & 1,309 & 1,041 & 353 & 1,278 & 1,010 & 322 \\
\hline NMVOC (mg) & 6 & 5 & 6 & 71 & 8 & 129 & 65 & 3 & 123 \\
\hline Particulates (mg) & 13 & 18 & 15 & 147 & 711 & 12 & 134 & 693 & -6 \\
\hline Sulphur dioxide (mg) & 32 & 31 & 32 & 1,548 & 3,808 & 149 & 1,515 & 3,777 & 118 \\
\hline
\end{tabular}




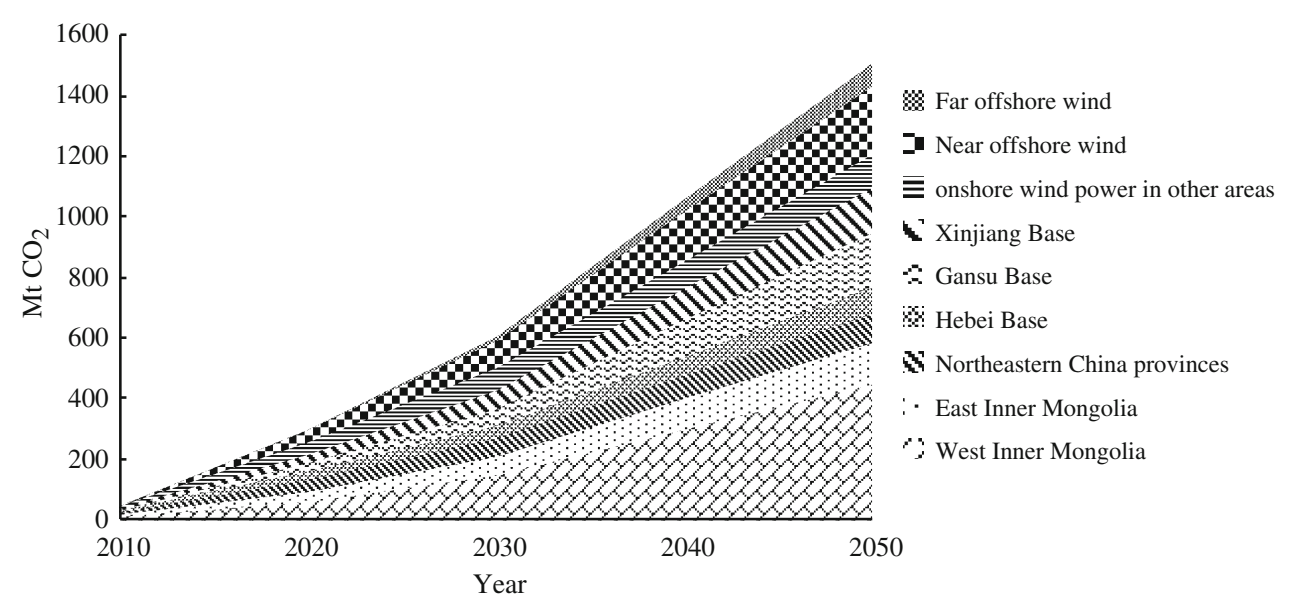

Fig. 7 Potential $\mathrm{CO}_{2}$ abatement of major wind farms in China

reaching the ground, causing increased rates of skin cancer and eye damaging to humans and is harmful to many biological species. The energy related activities will lead to ozone depletion directly or indirectly by emitting related pollutants, while wind power, as green power, will emit little pollutants leading to ozone depletion.

Besides, Global warming and climate changes mainly caused by $\mathrm{CO}_{2}$ will be mitigated. The greenhouse effect is caused by several greenhouse gasses, such as $\mathrm{CO}_{2}, \mathrm{CH}_{4}$, CFCs, halons, $\mathrm{N}_{2} \mathrm{O}$, ozone and peroxyacetyl nitrate, and has been increasingly associated with the contribution of $\mathrm{CO}_{2}$, which is estimated to contribute about $50 \%$ to the anthropogenic greenhouse effect. Greenhouse effect will result in a rise of the earth's temperature and cause climate changes, which will have a wide range of effects on human activities all over the world. The climate changes include the temperature changes of every season, precipitation fluctuations, extreme weather events, sea level increase, and glaciers melting, which will impact the growth of plants, bring diseases associated with weather, such as influenza, and threaten the existence of coastal cities, etc. $\mathrm{CO}_{2}$ emissions abatement is a significant contribution in environmental benefit via replacing coal power by wind power, which will mitigate the Global warming and climate changes.

Of course, large-scale development of wind power may have some negative impacts on the environment, such as land use, noise, visual impact, bird migration and electromagnetic radiation, but compared with other conventional energy sources, especially coal-fired electricity generation, wind power's impact in these areas is much lower or even avoidable.

\section{Strategic perspective development of wind power in China}

In just four short years, production of China's wind turbine manufacturing industry had been scaled up significantly with four of them now ranking in the world's top ten list. The industry chain has been established and improved, covering technology research and development; component manufacturing; turbine assembly, testing and certification; wind farm development and other associated services. As market competitiveness continues to grow, China has solid foundations for large-scale wind power development and takes advantage of this most developed commercialized renewable energy technology.

To meet the demand for large-scale renewable energy development, China has to position itself to accelerate power system development for the sake of the state, with a strategic perspective. Since wind power development is closely linked with the development of its grid infrastructure, operation and dispatch issues, China has to manage and ensure it to accommodate greater shares of variable wind power. Future power systems will need to feature more flexibility on the demand side as well as on the supply side if they are to optimise the full range of non-polluting, low-carbon energy sources, while maintaining security and reliability.

\subsection{Issues on grid integration}

In anticipation of the continued expansion of wind power, the following key issues of inter-regional wind power integration require further attention.

(1) Continued efforts should be made to expand integration of wind power within provinces in western China. Smart grid technologies, smart power devices, energy storage facilities and electric vehicles should be deployed to enable flexible regulation of load to match power demand and greatly increase the capacity for integrating wind power and other fluctuating power sources.

(2) Transmission from west to east should be improved and optimised through widespread adoption of 
flexible transmission technology, especially ultrahigh-voltage DC transmission and superconductive transmission. Transmission system cost recovery mechanisms need to be improved to maximise transmission line capacity and cost-effectiveness.

(3) Wider deployment of smart distribution network technologies and micro-networks should be encouraged, to improve decentralised wind power integration and accommodation potential in eastern and central China.

\subsection{Issues on wind power technology}

China has a continuous need for research and development on wind power technologies for large-scale deployment of wind energy beyond 2030. R\&D depends on many factors, including wind power targets, wind resource characteristics, power load distribution and power grid distribution. Although China's wind power manufacturing industry grew quickly from 2006 to 2010, advanced largecapacity turbine system should be improved to meet the needs of the wind power supply chain and to ensure wind turbine quality and reliability.

(1) Enhancement of wind resource assessment technical standards and technical capability;

(2) Development of wind resource database and application services;

(3) Improvement of turbine performance;

(4) Enhancement of the quality of the wind system components;

(5) Improvement of the materials for the wind turbine blades and associated components;

(6) Incorporation of the storage technologies for improvement of the grid integration.

\subsection{Issues on offshore wind farm construction}

Although land-based wind farm technology is relatively mature, but efforts should be made to develop micro-siting techniques to continuously improve planning, design and operation of wind farms, especially in complex terrain. The direction of development is poised to improve the wind power system design on choosing sites, particularly for hilly, mountainous and other complex terrain. Regarding the offshore wind power development, especially deepwater wind farm development and construction, China is still lacking behind. R\&D activities need to be enhanced, based on China's specific planning and construction conditions. Project demonstrations should be accelerated to work out technical systems for far offshore and deepwater wind farms.

\subsection{Issues on system coordination}

As the installed capacity of wind power increases, better coordination on wind power systems become vital. Accurate forecasts support reliable operation of the power system, effective management and maximum integration of wind power, while reducing system operating costs and the requirement for capacity margin. Sophisticated statistical techniques are required to provide forecasts ranging from 3 to $72 \mathrm{~h}$ ahead of the time of delivery. It provides centralized and distributed wind power forecast service which will operate jointly with power grid dispatch, weather departments and wind farms to provide effective dispatching support. Alongside improvements in power grid infrastructure and operation techniques, and traditional AC transmission for large-scale wind farms and long distances, more flexible DC, high-voltage DC (HVDC), superconductive and low-frequency transmission technologies will need to be improved, especially for offshore wind farm electricity. Development of interconnection technologies on using super-high-voltage technologies including dynamic reactive power compensation, series compensation/TCSC, controllable high resistance, and automatic voltage control (AVC) are required to improve wind power output and energy quality, as well as to enhance safe operation of the power system.

\section{Conclusion}

In conclusion, the macroscopic analysis performed in the paper provides a comprehensive status quo on the wind power development in China. It indicates that energy demand in China will increase rapidly in the next few decades following its economic and social development. The prevailing policy for a clean energy strategy supports the use of wind power as the main energy technology for realizing the low carbon target. Her potential of wind power development is proven to be tremendous by considering the quality and quantity of the wind resources as reported by the National Climate Centre of China. Results on the wind power resources analysis indicate that the wind power installed capacity in China is in a leading position among the world class countries. The strategic position of the wind power development is affirmed by understanding its statutory relationship with the Renewable Energy Law 2005 as summarized in the paper. Results of the analysis on the various attributes in relation to the associated legal and regulatory framework support that wind power generation contributes to the energy saving and emission reduction and in turn to the successful implementation of the sustainable energy policy. The manufacturing capability of wind power generation units including their operational 
efficiency and the grid integration practices are examined and reported in the paper. Results reveal that the success in dominating the market share in China by the domestic wind power manufacturing enterprises indicates its readiness to go for international markets. In the benefits analysis, the effect of the emission reduction contributed from the use of the wind power is quantified. Finally, the prospective strategic development of wind power in China is examined and suggestions are provided to address on the various developmental issues, including grid integration, R\&D on wind power technology, wind farm construction and system coordination.

Acknowledgements The financial supports provided by the State Natural Sciences Fund (71071053), Beijing Energy Development and Research Base Projects and the RGC Hong Kong (GRF Project: PolyU 5279/09E) for carrying out the research work as reported in this paper are acknowledged.

Open Access This article is distributed under the terms of the Creative Commons Attribution License which permits any use, distribution, and reproduction in any medium, provided the original author(s) and the source are credited.

\section{References}

[1] Liao CP, Jochem E, Zhang Y et al (2010) Wind power development and policies in China. Renew Energy 35(9):1879-1886

[2] Kang J, Yuan J, Hu Z et al (2012) Review on wind power development and relevant policies in China during the 11th Five-Year-Plan period. Renew Sustain Energy Rev 16(4): 1907-1915

[3] Lewis JI (2011) Building a national wind turbine industry: experiences from China, India and South Korea. Int J Technol Glob 5(3/4):281-305

[4] Teodorescu R, Liserre M (2011) Grid converters for photovoltaic and wind power systems. Wiley-IEEE, New York

[5] Zhao ZY, Zuo J, Fan LL et al (2011) Impacts of renewable energy regulations on the structure of power generation in China-a critical analysis. Renew Energy 36(1):24-30

[6] Zhang N, Lior N, Jin H (2011) The energy situation and its sustainable development strategy in China. Energy 36(6): 3639-3649

[7] Zhang X, Chang S, Huo M et al (2009) China's wind industry: policy lessons for domestic government interventions and international support. Clim Policy 9(5):553-564

[8] Zhao ZY, Zuo J, Zillante G et al (2010) Critical success factors for BOT electric power projects in China: thermal power versus wind power. Renew Energy 35(6):1283-1291

[9] Xu J, He D, Zhao X (2010) Status and prospects of Chinese wind energy. Energy 35(11):4439-4444
[10] Markard J, Petersen R (2009) The offshore trend: structural changes in the wind power sector. Energy Policy 37(9):3545-3556

[11] The Climate (2011) Renewable energy development targets in China's 12th Five Year Plan adjusted upwards. Briefing note

[12] UK: Vestas, GE Lead among wind turbine manufacturers in 2012. ofshoreWIND.biz, 2012

[13] Zhang ZX (2010) China in the transition to a low-carbon economy. Energy Policy 38(11):6638-6653

[14] Ma L, Liu P, Fu F et al (2011) Integrated energy strategy for the sustainable development of China. Energy 36(2):1143-1154

[15] Liu Y, Shi J, Yang Y et al (2009) Piecewise support vector machine model for short-term wind-power prediction. Int $\mathbf{J}$ Green Energy 6(5):479-489

[16] Ling Y, Cai X (2012) Exploitation and utilization of the wind power and its perspective in China. Renew Sustain Energy Rev 16(4):2111-2117

[17] Zhao P, Wang J, Xia J et al (2012) Performance evaluation and accuracy enhancement of a day-ahead wind power forecasting system in China. Renew Energy 43:234-241

[18] Ru P, Zhi Q, Zhang F et al (2012) Behind the development of technology: the transition of innovation modes in China's wind turbine manufacturing industry. Energy Policy 43:58-69

\section{Author Biographies}

Zhongfu TAN was born in China, in 1964. He received the Ph.D. degree from the Dalian University of Technology in 1994. His current research interests include energy economics, electric power risk management, power system optimization and development strategy.

H. W. NGAN received the Ph.D. degree from the University of Strathclyde respectively in 1993 . His current research interests include power market reform and simulation, sustainable energy development, integration of renewable energy to smart grid and energy policy planning.

Yang WU received the Ph.D. degree from the Hong Kong Polytechnic University in 2013. His current research interests include electric power system planning, sustainable energy development.

Huijuan ZHANG was born in China, in 1986. She is Ph.D. student of the North China Electric Power University. Her current research interests include energy economics and electric power risk management.

Yihang SONG was born in China, in 1986. She is Ph.D. student of the North China Electric Power University. His current research interests include power economics, electric power risk management and power system optimization.

Chao YU was born in China, in 1984. He received the Ph.D. degree from the North China Electric Power University in 2012. His current research interests include electric power system planning and electric power economics. 